Western University

Scholarship@Western

Aboriginal Policy Research Consortium International (APRCi)

$11-2-2009$

\title{
Victims of violence among Indigenous mothers living with dependent children
}

Kyllie Cripps

Catherine M. Bennett

Lyle C. Gurrin

David M. Studdert

Follow this and additional works at: https://ir.lib.uwo.ca/aprci

Part of the Other Public Health Commons

Citation of this paper:

Cripps, Kyllie; Bennett, Catherine M.; Gurrin, Lyle C.; and Studdert, David M., "Victims of violence among Indigenous mothers living with dependent children" (2009). Aboriginal Policy Research Consortium International (APRCi). 317.

https://ir.lib.uwo.ca/aprci/317 


\title{
Victims of violence among Indigenous mothers living with dependent children
}

\author{
Kyllie Cripps, Catherine M Bennett, Lyle C Gurrin and David M Studdert
}

M any Indigenous communities have a high prevalence of violence. ${ }^{1-6}$ In June 2007, findings from the Northern Territory Board of Inquiry into the Protection of Aboriginal Children from Sexual Abuse ${ }^{1}$ galvanised public attention and prompted a dramatic policy response from the Australian Government - the ongoing Northern Territory Intervention. ${ }^{7}$

Violence against Indigenous women and children raises special concerns, both in Australia and internationally. ${ }^{3,8,9}$ Indigenous women and children are arguably more vulnerable to violence and more likely to be victims of it than any other section of Australian society. ${ }^{10}$ However, the epidemiology of violence in Indigenous communities in Australia remains little studied and poorly understood. For example, there has been virtually no empirical investigation of risk factors, despite the opportunities created by several national surveys of Aboriginal and Torres Strait Islander people..$^{11,12}$

We used data from the 2002 National Aboriginal and Torres Strait Islander Social Survey (NATSISS) to analyse individual and household characteristics of respondents who reported being victims of violence in the previous 12 months. The analysis focused on Indigenous women with dependent children, as this population is known to be at elevated risk of violence,, 10 and as the repercussions of violence against mothers are amplified by the effects on their children, who often witness the violence itself or its visible consequences. ${ }^{1}$ The broad goal of this study was to advance understanding of violence in Indigenous communities to help inform policy and practice aimed at addressing the problem.

\section{METHODS}

\section{Data source}

The Australian Bureau of Statistics (ABS) conducted the 2002 NATSISS between August 2002 and April 2003. ${ }^{11}$ The survey elicited information from 9359 Indigenous people in 5887 households - about one in 30 of the national Indigenous population aged 15 years or older. Questions gathered individual and family sociodemographic data and data on key areas relevant to social

\section{ABSTRACT}

Objective: To identify individual and household factors associated with violence among Australian Indigenous women with dependent children.

Design and participants: Univariate and multivariable analysis of data from the 2002 National Aboriginal and Torres Strait Islander Social Survey, stratified by area.

Main outcome measure: Self-reported experience of being a victim of violence in the previous year.

Results: One in four Indigenous women living with dependent children younger than 15 years reported being victims of violence in the previous year; this corresponds to an estimated 24221 Indigenous mothers (95\% Cl, 21 507-26 935) nationwide. Violence was more prevalent in regional areas and cities than remote areas. In remote areas, mothers who had been removed from their natural families during childhood had nearly threefold greater odds of being victims of violence (odds ratio [OR], 2.90; 95\% Cl, 1.82-4.61); in non-remote areas, the odds were $72 \%$ greater $(\mathrm{OR}, 1.72 ; 95 \% \mathrm{Cl}, 1.23-2.39)$. Older maternal age ( $\geqslant 45$ years) was associated with lower odds of experiencing violence in both non-remote areas $(\mathrm{OR}, 0.39 ; 95 \% \mathrm{Cl}, 0.25-0.60)$ and remote areas $(\mathrm{OR}, 0.46 ; 95 \% \mathrm{Cl}$, $0.30-0.70)$. Women with partners residing in the household faced lower odds of violence in both non-remote areas $(\mathrm{OR}, 0.54 ; 95 \% \mathrm{Cl}, 0.41-0.72)$ and remote areas $(\mathrm{OR}, 0.46$; $95 \% \mathrm{Cl}, 0.32-0.67)$.

Conclusions: The prevalence of violence against Indigenous mothers with young children is alarmingly high across remote and non-remote areas. This study identified distinctive characteristics of victims, but further research is needed to assess potential risk factors, such as history of removal from natural family.

MJA 2009; 191: 481-485

policy, including health, education, work, community and cultural factors, social networks, crime, and behaviours relevant to population health, such as substance use and violence.

The survey was designed to provide reliable estimates at the national level. Sampling and recruitment techniques are described in detail elsewhere. ${ }^{13}$ In summary, participants were identified by randomly selecting communities and dwellings within those communities, and by using a stratified multistage method to select dwellings in non-community areas. Up to three people were surveyed in each sampled dwelling. Wherever possible, this was done through personal interviews conducted by trained ABS interviewers.

\section{Study sample}

Of the 9359 NATSISS respondents, 57\% (5343) were female, and $67 \%$ of these (3589) reported living with dependent children younger than 15 years. These 3589 mothers are the focus of this analysis. We imposed the 14-year age cut-off on depend- ants as older children might themselves have been sampled as respondents and might have had dependants of their own.

\section{Outcome variable}

The NATSISS included a module that sought to identify victims of violent assault. It asked, "In the last 12 months, did anyone, including people you know, use physical force or violence against you?" This was followed by a similar question with "use" replaced by "try to use". The ABS collapsed responses from these two questions into a single variable, designating respondents as either a "victim of physical or threatened violence" or not.

Based on pre-testing by the ABS, some NATSISS questions were reworded for use in remote areas of Western Australia, South Australia, Queensland and the Northern Territory. ${ }^{13}$ To minimise language and comprehension difficulties in these states, the violence questions were modifed to: "In the last year, did anybody start a fight with you or beat you up?" and "In the last year, did anybody try to or say they were going to hit you or fight with you?" 
1 Indigenous women living with dependent children who participated in the 2002 National Aboriginal and Torres Strait Islander Social Survey, by area of residence and status as victims of violence

\begin{tabular}{lccc} 
& & \multicolumn{2}{c}{ Victims of violence } \\
\cline { 3 - 4 } Remoteness area class* & Total no. & No. & Weighted \% within area \\
\hline Major cities & 494 & 137 & $25.4 \%$ \\
Inner regional & 450 & 132 & $28.6 \%$ \\
Outer regional & 932 & 267 & $28.0 \%$ \\
Remote and very remote & 1713 & 386 & $21.4 \%$ \\
All areas & 3589 & 922 & $25.3 \%$ \\
\hline
\end{tabular}

* According to the Australian Standard Geographical Classification.

\section{Exposure variables}

We examined the association between positive responses to the violence questions and four individual variables (age, labour force status, level of education, and removal from natural family) and five household variables (racial composition, partner/husband resident, other adults resident, income, and tenure type). These exposure variables were selected as they are recognised or hypothesised predictors of violence against women, based chiefly on studies of family and intimate partner violence. ${ }^{14-16}$ Although our study was not confined to these forms of violence, we believed it reasonable to draw from these sources as other evidence indicates that family violence is prominent in women's experiences of violence in Indigenous communities. ${ }^{17}$

All but two of the nine exposure variables included in the analysis were binary or categorical variables. Mother's age in the NATSISS was a continuous variable up to 64 years and categorical thereafter; we coded age into four categories (15-24, 25-34, 3544 , and $\geqslant 45$ years).

Household income was a continuous variable, expressed in terms of equivalised household gross weekly income. (Equivalence scales adjust actual household income to account for the number and age of persons in the household. ${ }^{18}$ ) We created four categories for equivalised household gross weekly income $(<\$ 339, \$ 339-\$ 611$, $>\$ 612$, and unknown).

Several other potentially relevant individual variables (personal income, income source, speaks Indigenous language, identification with clan, and relatives removed) and household variables (number of dependents, residents and bedrooms) were available in the NATSISS. We elected not to include these variables in the analysis because of conceptual overlap with the exposure variables chosen or relatively high statistical correlation with those variables.

\section{Analysis}

Because of evidence that violence against women differs in pattern and nature between remote and non-remote communities, ${ }^{17,19,20}$ we stratified the analyses according to the remoteness area classes in the Australian Standard Geographical Classification (major cities, inner regional, outer regional, remote, and very remote), with the exclusion of "migratory". We created two strata: mothers residing in remote and very remote communities were examined separately from those residing in cities and regional areas.

Within each stratum, we used univariate and multivariable logistic regression to compare characteristics between mothers who reported having experienced violence and those who reported not having experienced violence. The dependent variable in all analyses was a binary variable, distinguishing victims of violence from non-victims. The independent variables were the four individual and five household exposure variables described above. The exception was education, which was excluded from the multivariable models because its relationship with the dependent variable did not approach statistical significance in any of the univariate analyses. (We confirmed that its inclusion in the multivariable models did not affect their main findings.)

To accommodate the complex survey design, we weighted descriptive statistics and corrected standard errors using the replicate weights provided and the jack-knife method recommended by the ABS. ${ }^{12}$ The regression analyses were unweighted. All statistical code was written using the STATA software package, version 10.0 (StataCorp, College Station, Tex, USA), and processed through the ABS's Remote Access Data Laboratory.

\section{RESULTS}

\section{Rates of violence}

A quarter (25.3\%) of Indigenous women with dependent children younger than 15 years reported being victims of violence in the previous 12 months (Box 1). At the national level, this corresponds to 24221 mothers (95\% CI, 21 507-26 935).

The proportion of mothers who reported experiencing violence was greater in nonremote than in remote areas. The prevalence of victimhood was significantly higher in inner regional areas and outer regional areas than in remote and very remote areas $(28.6 \% \mathrm{v} 21.4 \%, P=0.001$, and $28.0 \% \mathrm{v}$ $21.4 \%, P<0.001$, respectively), and there was a trend toward a higher prevalence in cities $(25.4 \%$ v $21.4 \% ; P=0.06)$.

\section{Univariate analyses}

Cities and regional areas. In these areas, younger mothers had higher odds of being victims of violence than mothers aged between 35 and 44 years, and older mothers had lower odds (Box 2). Unemployed mothers had higher odds of violence (odds ratio [OR], 1.65; 95\% CI, 1.32-2.07), as did mothers who had been removed from their natural family during childhood (OR, 1.67; 95\% CI, 1.22-2.28). At the household level, all Indigenous composition (OR, 1.44; 95\% CI, 1.16-1.79) and renting (OR, 1.94; 95\% CI, 1.48-2.54) were associated with a higher risk of victimhood. On the other hand, low income (OR, 0.47; 95\% CI, 0.35-0.63) and high income (OR, 0.53; 95\% CI, 0.35-0.80), both relative to poverty, and having a partner or husband residing in the dwelling (OR, $0.50 ; 95 \% \mathrm{CI}, 0.41-0.62$ ) were all associated with lower risk of victimhood.

Remote and very remote areas. Fewer factors were significantly associated with victimhood in remote areas than in non-remote areas (Box 2). Older maternal age ( $\geqslant 45$ years) was associated with a reduced risk of victimhood (OR, 0.58 ; 95\% CI, 0.39-0.86), as it was in non-remote areas, although the risks among younger mothers were not significantly higher than in the reference age group (35-44 years). There was a strong association between removal from one's natural family and victimhood (OR, 2.31; 95\% CI, 1.46-3.58). With respect to household composition, the odds of being a victim of violence were lower among mothers with a partner or husband residing in the house (OR, $0.58 ; 95 \% \mathrm{CI}, 0.46-0.73$ ), and the odds were higher with an adult other than a 
2 Individual and household characteristics of Indigenous women with dependent children who were victims of violence*

Cities and regional areas

Remote and very remote areas

\begin{tabular}{|c|c|c|c|c|c|c|c|c|c|c|}
\hline \multirow[b]{2}{*}{ Characteristics } & & \\
\hline & Victims & n-victi & dds ratio & $95 \% \mathrm{Cl}$ & $P$ & Victims & Non-victims & Odds ratio & $95 \% \mathrm{Cl}$ & $P$ \\
\hline \multicolumn{11}{|l|}{ Age group (years) } \\
\hline $15-24$ & $35 \%$ & $27 \%$ & 1.39 & $1.06-1.84$ & 0.02 & $36 \%$ & $29 \%$ & 1.01 & $0.74-1.38$ & 0.93 \\
\hline $25-34$ & $35 \%$ & $33 \%$ & 1.36 & $1.05-1.76$ & 0.02 & $30 \%$ & $29 \%$ & 0.99 & $0.73-1.34$ & 0.95 \\
\hline 35-44 (reference) & $21 \%$ & $26 \%$ & & & & $23 \%$ & $21 \%$ & & & \\
\hline$\geqslant 45$ & $8 \%$ & $15 \%$ & 0.45 & $0.29-0.68$ & $<0.001$ & $12 \%$ & $21 \%$ & 0.58 & $0.39-0.86$ & 0.006 \\
\hline Not employed & $76 \%$ & $66 \%$ & 1.65 & $1.32-2.07$ & $<0.001$ & $56 \%$ & $58 \%$ & 0.89 & $0.71-1.12$ & 0.31 \\
\hline \multicolumn{11}{|l|}{ Highest level of education } \\
\hline Tertiary (reference) & $19 \%$ & $18 \%$ & & & & $9 \%$ & $10 \%$ & & & \\
\hline Years 11 and 12 & $27 \%$ & $28 \%$ & 0.85 & $0.62-1.17$ & 0.33 & $26 \%$ & $19 \%$ & 0.97 & $0.64-1.47$ & 0.88 \\
\hline Year 10 and below & $53 \%$ & $53 \%$ & 0.96 & $0.73-1.27$ & 0.79 & $60 \%$ & $64 \%$ & 0.90 & $0.63-1.30$ & 0.58 \\
\hline Unknown & $<1 \%$ & $1 \%$ & 0.52 & $0.17-1.58$ & 0.25 & $4 \%$ & $7 \%$ & 0.60 & $0.31-1.16$ & 0.13 \\
\hline Removed from natural family ${ }^{\dagger}$ & $19 \%$ & $8 \%$ & 1.67 & $1.22-2.28$ & 0.001 & $7 \%$ & $3 \%$ & 2.31 & $1.46-3.58$ & $<0.001$ \\
\hline \multicolumn{11}{|l|}{ Household composition } \\
\hline All Indigenous members ${ }^{\ddagger}$ & $68 \%$ & $61 \%$ & 1.44 & $1.16-1.79$ & 0.001 & $93 \%$ & $91 \%$ & 0.94 & $0.64-1.39$ & 0.76 \\
\hline Partner/husband present ${ }^{\ddagger}$ & $28 \%$ & $46 \%$ & 0.50 & $0.41-0.62$ & $<0.001$ & $45 \%$ & $58 \%$ & 0.58 & $0.46-0.73$ & $<0.001$ \\
\hline$>1$ adult (besides partner/husband) $)^{\ddagger}$ & $34 \%$ & $27 \%$ & 1.13 & $0.90-1.41$ & 0.28 & $44 \%$ & $33 \%$ & 1.39 & $1.11-1.76$ & 0.005 \\
\hline \multicolumn{11}{|l|}{ Equivalised gross weekly income } \\
\hline Poor $(<\$ 339)$ (reference) & $69 \%$ & $55 \%$ & & & & $54 \%$ & $53 \%$ & & & \\
\hline Low $(\$ 339-\$ 611)$ & $15 \%$ & $26 \%$ & 0.47 & $0.35-0.63$ & $<0.001$ & $24 \%$ & $18 \%$ & 1.19 & $0.89-1.60$ & 0.23 \\
\hline High (> \$612) & $7 \%$ & $9 \%$ & 0.53 & $0.35-0.80$ & 0.003 & $5 \%$ & $5 \%$ & 0.80 & $0.45-1.40$ & 0.43 \\
\hline Unknown & $9 \%$ & $9 \%$ & 0.88 & $0.63-1.23$ & 0.46 & $16 \%$ & $23 \%$ & 0.76 & $0.56-1.02$ & 0.07 \\
\hline \multicolumn{11}{|l|}{ Tenure } \\
\hline Owner (reference) & $21 \%$ & $28 \%$ & & & & $7 \%$ & $7 \%$ & & & \\
\hline Renter & $78 \%$ & $71 \%$ & 1.94 & $1.48-2.54$ & $<0.001$ & $89 \%$ & $84 \%$ & 0.95 & $0.62-1.44$ & 0.80 \\
\hline Other & $1 \%$ & $1 \%$ & 1.50 & $0.57-3.93$ & 0.41 & $4 \%$ & $9 \%$ & 0.62 & $0.28-1.36$ & 0.24 \\
\hline
\end{tabular}

husband or partner residing there (OR, 1.39; 95\% CI, 1.11-1.76).

\section{Multivariable analyses}

There was a strong positive association between being a victim of violence and having been removed from one's natural family during childhood in both multivariable models (Box 3). In non-remote areas, mothers with this history had $72 \%$ greater odds of being a victim of violence than those without this history (OR, 1.72; 95\% CI, 1.23-2.39), and in remote areas, the odds were nearly three times greater (OR, 2.90; 95\% CI, 1.82-4.61). Older maternal age was associated with a lower risk of violence in both non-remote areas (OR, 0.39; 95\% CI, 0.25-0.60) and remote areas (OR, 0.46; 95\% CI, 0.30-0.70). The presence of a partner or husband living in the house also appeared to be protective in both nonremote areas (OR, 0.54; 95\% CI, 0.41-0.72) and remote areas (OR, 0.46; 95\% CI, 0.320.67 ). Low income relative to poverty was associated with lower risk of violence in non-remote areas (OR, 0.64; 95\% CI, 0.460.88 ), but not in remote areas. There was no significant correlation between high income and risk of violence in either non-remote or remote areas.

\section{DISCUSSION}

This study showed that one in four mothers with dependants younger than 15 years who responded to the 2002 NATSISS reported being victims of violence in the previous year. The violence was not confined to remote communities — indeed, reported rates were higher in regional and urban areas. We found similar predictors across remote and nonremote areas: mothers who had been removed from their natural families were significantly more likely to have experienced violence, whereas older mothers and those who lived with their male partners were significantly less likely to have done so.

Our findings fit with theoretical and qualitative research into Indigenous violence over the past decade. ${ }^{1-6}$ Causes are complex, involving multiple inter-related factors, but have been conceptualised in two groups. ${ }^{2}$ Group 1 factors relate to the unique experiences of Indigenous populations, including colonisation policies and practices, dispossession and cultural dislocation, and damage to the family structure due to removal of children. Group 2 factors reflect broader social determinants of violence relevant to both Indigenous and non-Indigenous populations, including unemployment, poverty, welfare dependency, past history of abuse, substance addictions, racism and social marginalisation.

Evidence to date that this range of factors operates in the context of Indigenous violence comes essentially from qualitative research. ${ }^{1-6,21-23}$ Our study breaks new 
3 Multivariable predictors of victims of violence among Indigenous women living with dependent children*

\begin{tabular}{|c|c|c|c|c|c|c|}
\hline \multirow[b]{2}{*}{ Characteristics } & \multicolumn{3}{|c|}{$\begin{array}{l}\text { Cities and } \\
\text { regional areas }\end{array}$} & \multicolumn{3}{|c|}{$\begin{array}{c}\text { Remote and } \\
\text { very remote areas }\end{array}$} \\
\hline & $\begin{array}{l}\text { Odds } \\
\text { ratio }\end{array}$ & $95 \% \mathrm{Cl}$ & $P$ & $\begin{array}{l}\text { Odds } \\
\text { ratio }\end{array}$ & $95 \% \mathrm{Cl}$ & $P$ \\
\hline \multicolumn{7}{|l|}{ Age group (years) } \\
\hline $15-24$ & 1.19 & $0.88-1.60$ & 0.27 & 0.94 & $0.67-1.31$ & 0.71 \\
\hline $25-34$ & 1.30 & $1.00-1.71$ & 0.05 & 0.98 & $0.72-1.34$ & 0.90 \\
\hline$\geqslant 45$ & 0.39 & $0.25-0.60$ & $<0.001$ & 0.46 & $0.30-0.70$ & $<0.001$ \\
\hline Not employed & 1.27 & $0.97-1.65$ & 0.08 & 0.86 & $0.67-1.11$ & 0.25 \\
\hline Removed from natural family ${ }^{\dagger}$ & 1.72 & $1.23-2.39$ & 0.001 & 2.90 & $1.82-4.61$ & $<0.001$ \\
\hline \multicolumn{7}{|l|}{ Household composition } \\
\hline All Indigenous ${ }^{\ddagger}$ & 0.96 & $0.73-1.24$ & 0.74 & 0.93 & $0.60-1.43$ & 0.73 \\
\hline Partner/husband present ${ }^{\ddagger}$ & 0.54 & $0.41-0.72$ & $<0.001$ & 0.46 & $0.32-0.67$ & $<0.001$ \\
\hline$>1$ adult (besides partner/husband) ${ }^{\ddagger}$ & 0.87 & $0.65-1.16$ & 0.33 & 0.82 & $0.57-1.20$ & 0.31 \\
\hline \multicolumn{7}{|l|}{ Gross weekly household income } \\
\hline Low (\$339-\$611) & 0.64 & $0.46-0.88$ & 0.007 & 1.20 & $0.88-1.64$ & 0.25 \\
\hline High (> \$612) & 0.93 & $0.57-1.53$ & 0.79 & 0.80 & $0.43-1.48$ & 0.47 \\
\hline Unknown & 1.10 & $0.78-1.57$ & 0.58 & 0.78 & $0.57-1.07$ & 0.13 \\
\hline Renter & 1.33 & $0.97-1.83$ & 0.08 & 0.86 & $0.53-1.37$ & 0.52 \\
\hline
\end{tabular}

* Reference groups are: age 35-44 years; employed; not removed from natural family; not all Indigenous; partner/husband not living in household; no other adults living in household; poor ( $<\$ 339$ per week); home owner or other. †During childhood. ¥These are separate binary variables, not categories of a "household composition" variable.

ground by identifying statistically significant characteristics of victims of violence from a national sample. Our finding that removal from natural family is strongly associated with an increased risk of victimhood in both remote and non-remote areas, after adjusting for other well established Group 2 factors such as unemployment status and income, is especially troubling. As well as suggesting that Group 1 factors may be influential, this result highlights the formidable and complex challenges that confront efforts to combat violence in Indigenous communities.

Instances of neglect, abuse, exploitation and violence among Indigenous children removed from their natural families have been extensively documented. ${ }^{24,25}$ There is growing awareness of the trauma produced by forced separation. ${ }^{25}$ However, evidence of its lasting impact on the adult lives of children who experienced it is incomplete and continues to accumulate. The prominence of removal as a factor associated with violence in our analysis adds to this evidence base. It also suggests that victimhood status imposed early may become entrenched.

Identification of older maternal age as a protective factor resonates with findings from studies focused specifically on domestic and family violence. ${ }^{26,27}$ It may be due to the ability of older women to better negotiate risky interpersonal situations, although this explanation requires further investigation. Closer analysis should pay careful attention to the precise nature of the relationships between older mothers and young children. Previous qualitative research suggests, for example, that some older Indigenous women who self-identify as mothers may in fact be grandmothers of the dependents. ${ }^{28}$

Multivariable analyses showed that the presence of a male partner in the house reduced mothers' odds of experiencing violence by half in both non-remote and remote areas. This is a novel finding in Australian research on Indigenous violence, although previous international research has shown higher rates of violence among divorced and separated women. ${ }^{27}$ One explanation is that a regular male presence, a stable relationship, or both, deter attackers. An alternative explanation that warrants serious consideration and research is under-reporting: respondents may have been reluctant to report their experiences of violence if their partner was nearby, particularly if the partner was the perpetrator. A third explanation, given that we observed a correlation but cannot infer causality, is that women harmed by cohabiting partners are less likely to continue living with them.

Our study has several limitations. First, the dataset released by ABS collapsed responses to questions about actual and threatened violence into one variable, preventing their separate analysis. Second, the survey lacked detail and context regarding the violence. For example, it did not elicit whether the violent events occurred inside or outside the home, nor did it establish the relationship of the perpetrator to the victim. Third, because analyses such as this rely on cross-sectional survey data, they cannot establish causal relationships. Nonetheless, the associations identified provide a reasonable basis for flagging "at risk" subpopulations and launching further targeted investigations.

Although this study focused on the prevalence and correlates of violence among Indigenous mothers, the findings clearly have implications for the children in those families. Children living in homes in which violence occurs are vulnerable to physical, emotional and psychological abuse. . $^{2-32}$ They are at greater risk of anxiety, depression and behavioural disorders. In addition, the experience of violence in childhood is a risk factor for being both a victim and a perpetrator of violence in adulthood. ${ }^{29-32}$ Thus, a pernicious cycle of violence in Indigenous communities may develop through children and become intergenerational. ${ }^{1}$

Breaking that cycle presents a complex and difficult policy challenge. ${ }^{1,33}$ The distinctive characteristics identified in our study spotlight high-risk subgroups of women in urgent need of assistance. The findings should help guide the efforts of Indigenous communities struggling to address violence, and aid those from outside the communities who are formulating and delivering services to combat the problem. Because the children of these vulnerable women are secondary victims of the violence against their caregivers and role models, they would be indirect beneficiaries of effective prevention strategies.

\section{COMPETING INTERESTS}

None identified.

\section{AUTHOR DETAILS}

Kyllie Cripps, BA(Hons), PhD, Research Fellow ${ }^{1}$ Catherine M Bennett, PhD, MAppEpid, Associate Professor ${ }^{1,2}$

Lyle C Gurrin, PhD, Senior Lecturer ${ }^{1}$ 
David M Studdert, LLB, ScD, Federation Fellow and Professor ${ }^{1}$

1 Melbourne School of Population Health, University of Melbourne, Melbourne, VIC.

2 School of Health and Social Development, Deakin University, Melbourne, VIC (current address).

Correspondence: d.studdert@unimelb.edu.au

\section{REFERENCES}

1 Wild R, Anderson P. Ampe akelyernemane meke mekarle: "little children are sacred". Report of the Northern Territory Board of Inquiry into the Protection of Aboriginal Children from Sexual Abuse. Darwin: Northern Territory Government, 2007: 13. http:// www.nt.gov.au/dcm/inquirysaac/pdf/bipacsa_ final_report.pdf (accessed Apr 2009).

2 Cripps K. Indigenous family violence: from emergency measures to committed long term action. Aust Indig Law Rev 2007; 11: 7-18.

3 Dodson M. Violence, dysfunction, Aboriginality. Presented at the National Press Club, 2003; Jun 11; Canberra.

4 Gordon S, Hallahan K, Henry D. Putting the picture together - inquiry into response by government agencies to complaints of family violence and child abuse in Aboriginal communities. Perth: State Law Publisher, 2002.

5 New South Wales Aboriginal Child Sexual Assault Taskforce. Breaking the silence: creating the future. Addressing child sexual assault in Aboriginal communities in NSW. Sydney: NSW Attorney General's Department, 2006.

6 Robertson B. The Aboriginal and Torres Strait Islander Women's Task Force on Violence report. Brisbane: Queensland Government, 1999.

7 Northern Territory National Emergency Response Act 2007 (Cwlth).

8 International Indigenous Women's Forum. Mairin iwanka raya. Indigenous women stand against violence: a companion report to the United Nations Secretary-General's Study on Violence Against Women. New York: FIMI I (Foro International de Mujeres Indigenas), 2006.

9 Erturk Y. Promotion and protection of all human rights, civil, political, economic, social and cultural, including the right to development. Report of the Special Rapporteur on violence against women, its causes and consequences. Human Rights Council, Seventh Session, Agenda Item 3, 2008.

10 Blagg H. Crime, Aboriginality and the decolonisation of justice. Sydney: Hawkins Press, 2008.

11 Australian Bureau of Statistics. National Aboriginal and Torres Strait Islander Social Survey, 2002. Canberra: ABS, 2004. (ABS Cat. No. 4714.0.)

12 Australian Bureau of Statistics. National Aboriginal and Torres Strait Islander Health Survey, 2004-05. Canberra: ABS, 2004. (ABS Cat. No. 4715.0.)

13 Australian Bureau of Statistics. National Aboriginal and Torres Strait Islander Social Survey: expanded confidentialised unit record file, technical paper, 2002. Canberra: ABS, 2004. (ABS Cat. No. 4720.0.)

14 Romans S, Forte T, Cohen M, et al. Who is most at risk for intimate partner violence? A Canadian population-based study. J Interpers Violence 2007; 22: 1495-1514.

15 Brownridge DA. Male partner violence against aboriginal women in Canada: an empirical analysis. J Interpers Violence 2003; 22: 1495-1514.

16 Jewkes R, Levin J, Penn-Kekana L. Risk factors for domestic violence: findings from a South African cross-sectional study. Soc Sci Med 2002; 55: 1603-1617.

17 Al-Yaman F, Van Doeland M, Wallis M. Family violence among Aboriginal and Torres Strait Islander peoples. Canberra: Australian Institute of Health and Welfare, 2006. (AlHW Cat. No. IHW 17.)

18 Australian Bureau of Statistics. Household Expenditure Survey and Survey of Income and Housing: user guide, 2003-04. Canberra: ABS, 2006. (ABS Cat. No. 6503.0.)

19 Ferrante A, Morgan F, Indermaur D, Harding R. Measuring the extent of domestic violence. Sydney: Hawkins Press, 1996.

20 Hunter $\mathrm{BH}$, editor. Assessing the evidence on Indigenous socioeconomic outcomes: a focus on the 2002 NATSISS. Canberra: ANU ePress, 2006. (Monograph No. 26.)

21 Malcoe LH, Duran B, Montgomery JM. Socioeconomic disparities in intimate partner violence against Native American women: a crosssectional study. BMC Med 2004; 2: 20.

22 Oetzel J, Duran B. Intimate partner violence in American Indian and/or Alaska Native Communities: a social ecological framework of determinants and interventions. Am Indian Alask Native Ment Health Res 2004; 11: 49-68.
23 Raphael J, Tolman R. Trapped by poverty/ trapped by abuse: new evidence documenting the relationship between domestic violence and welfare. Ann Arbor, Mich: Project for Research on Welfare, Work, and Domestic Violence, 1997.

24 Human Rights and Equal Opportunity Commission. Bringing them home. Report of the National Inquiry into the Separation of Aboriginal and Torres Strait Islander Children from Their Families. Canberra: Australian Human Rights Commission, 1997.

25 Read P. A rape of the soul so profound: the return of the stolen generations. Sydney: Allen and Unwin, 1999.

26 Australian Bureau of Statistics. Women's safety Australia, 1996. Canberra: ABS, 1996. (ABS Cat. No. 4128.0.)

27 Garcia-Moreno C, Jansen HA, Ellsberg M, et al. WHO multi-country study on women's health and domestic violence against women: initial results on prevalence, health outcomes and women's responses. Geneva: World Health Organization, 2005. http://www.who.int/gender/violence/who_multicountry_study/en/ (accessed May 2009).

28 Hammill J. Granny rights: combating the granny burnout syndrome among Australian Indigenous communities. Development 2001; 44: 69-74.

29 Berrios DC, Grady D. Domestic violence: risk factors and outcomes. West J Med 1991; 155: 133-136.

30 Campbell JC, Lewandowski LA. Mental and physical health effects of intimate partner violence on women and children. Psych Clin North Am 1997; 20: 353-374.

31 McCauley J, Kern DE, Kolodner K, et al. Clinical characteristics of women with a history of child abuse: unhealed wounds. JAMA 1997; 277: 1362-1368.

32 Stover CS, Berkowitz S. Assessing violence exposure and trauma symptoms in young children: a critical review of measures. I Trauma Stress 2005; 18: 707-717.

33 Macklin J. National Council to Reduce Violence against Women and their Children. Speech delivered to National Indigenous Family Violence Forum, Parliament House, 2009, 30 Jan. http://www.jennymacklin.fahcsia.gov.au/internet/jennymacklin.nsf/content/indigenous_ forum_30jan09.htm (acccessed May 2009).

(Received 20 May 2009, accepted 27 Aug 2009) 